\title{
Simple nudges that are not so easy
}

\author{
DENISE DE RIDDER * \\ Department of Psychology, Utrecht University, Utrecht, The Netherlands \\ JORAM FEITSMA \\ School of Governance, Utrecht University, Utrecht, The Netherlands \\ MARIËTTE VAN DEN HOVEN \\ Ethics Institute, Utrecht University, Utrecht, The Netherlands \\ FLOOR KROESE \\ Department of Psychology, Utrecht University, Utrecht, The Netherlands \\ THOMAS SCHILLEMANS \\ School of Governance, Utrecht University, Utrecht, The Netherlands \\ MARCEL VERWEIJ \\ Philosophy Group, Wageningen University, Wageningen, The Netherlands \\ TINA VENEMA \\ Department of Psychology, Utrecht University, Utrecht, The Netherlands \\ ANASTASIA VUGTS \\ Philosophy Group, Wageningen University, Wageningen, The Netherlands \\ EMELY DE VET \\ Consumption and Healthy Lifestyles Group, Wageningen University, Wageningen, The Netherlands
}

\begin{abstract}
In this paper, we critically review three assumptions that govern the debate on the legitimacy of nudging interventions as a policy instrument: (1) nudges may violate autonomous decision-making; (2) nudges lend themselves to easy implementation in public policy; and (3) nudges are a simple and effective mean for steering individual choice in the right direction. Our analysis reveals that none of these assumptions are supported by recent studies entailing unique insights into nudging from three disciplinary outlooks: ethics, public administration and psychology. We find that nudges are less of a threat to autonomous choice than critics sometimes claim, making them ethically more legitimate than often assumed. Nonetheless, because their effectiveness is critically dependent on boundary conditions, their implementation is far from easy. The findings of this analysis thus suggest new opportunities for identifying when and for whom nudge interventions are preferable to more conventional public policy arrangements.
\end{abstract}

\footnotetext{
* Correspondence to: Utrecht University - Social, Health, and Organizational Psychology, Utrecht, The Netherlands. Email: d.t.d.deridder@uu.nl
} 


\section{Introduction}

More than a decade ago, nudges were introduced as a promising alternative to existing public policies that assume a citizen's ability and willingness to make choices in their own best long-term interests (Thaler \& Sunstein, 2008). Nudges capitalize on the insight from behavioural science that human decision-making is not always rational (as determined by 'narrow logical norms'; Gigerenzer, 2015), which may lead to suboptimal choices in the face of difficult trade-offs between immediate benefits and long-run advantages. This type of choice has been documented in a wide variety of domains with a major impact on both individual lives and society as a whole, including personal finance and unhealthy lifestyles (Szaszi et al., 2018). Nudges, which take the form of subtle hints towards more favourable options without forbidding alternative, less desirable options, can support individuals in making better decisions when hindered by myopia, inertia, lack of willpower (Bovens, 2009) or other documented biases in human reasoning.

Over the past 10 years, nudges have become a popular public policy instrument, as evidenced by the growing number of behavioural insight units that advise national governments on issues involving citizen choices (Whitehead et al., 2014; Halpern, 2015). International organizations such as the Organisation for Economic Co-operation and Development (OECD, 2017) and the World Bank (2015) have also shown interest in nudges as an alternative for education and persuasion to engage citizens with matters of personal and societal interest, including poverty, early childhood development, productivity and climate change. As the popularity of nudges as a new policy instrument has increased, however, so has the debate about their legitimacy (e.g., Hausman \& Welch, 2010; Johnson et al., 2012; Sunstein, 2015), with proponents arguing that nudges acknowledge the bounded rationality in human reasoning, a claim elaborated by research on the heuristics and biases that characterize most human decision-making (Kahneman, 2003). From this perspective, given that such subtle hints neither coerce nor forbid but involve only a gentle push towards what for most individuals will be the better choice, nudging can contribute to more effective public policies while still respecting citizen autonomy. Opponents, in contrast, criticize the manipulative nature of nudges, as they would exploit inherent weaknesses in human reasoning of which individuals themselves are unaware, which violates a liberal democratic society's requirement of transparency in public policy objectives (e.g., Grüne-Yanoff, 2012; Wilkinson, 2013; Nys \& Engelen, 2017). Critics also express concern that government-initiated behaviour change will contribute to the rise of a 'psychological state' that interferes with the requirements of 
human dignity and free choice, thereby posing a threat to citizen autonomy (Jones et al., 2013; Leggett, 2014).

Whichever the stance taken, both proponents and opponents agree that autonomy is key to determining legitimacy in governmental use of nudging interventions (e.g., Hansen \& Jespersen, 2013), while apparently assuming that behaviour change via nudging is easily achieved. Not only do they view nudges as a 'simple' (Mani et al., 2013; Martin et al., 2014) tool for generating 'big returns on small investments' (Benartzi et al., 2017), they imagine them to be easy to implement in public policy (Dolan et al., 2012; Service et al., 2014; Halpern, 2015; Benartzi et al., 2017; Mols et al. 2018; OECD, 2018). We, in contrast, posit that these assumptions are not only invalid, but also hinder progress in determining how and when nudges can be most effectively and efficiently applied in public policy. Specifically, we argue that these assumptions require closer scrutiny from each of the disciplines involved in nudging research before significant steps can be taken to employ nudges to steer individual choices for the benefit of all.

To date, however, rather than integrated multidisciplinary effort to reflect critically on these basic assumptions of nudging development and implementation, consideration has occurred in isolation, with behavioural scientists interested in nudging's effectiveness, philosophers considering its ethical requirements and political scientists examining how nudging insights can feed efficiently into public administration procedures. Hence, in this paper, we demonstrate the inefficacy of this isolationist approach by drawing on research from the Welfare Improvement through Nudging Knowledge (WINK) project, which examines nudging from the perspective of three core disciplines: ethics, public administration and psychology. Empirical studies from each of these disciplinary perspectives in our project have recently been published (e.g., Feitsma, 2018, 2019; Vugts et al., 2018; Venema et al., 2019, 2020a, 2020b). Here, we focus on a synthesized review of the results from these studies, supplemented with literature discussing the issues that we identified as common themes in our multidisciplinary approach.

Based on this analysis, we argue not only that nudging threatens autonomy less than many critics assume, but also that nudging interventions may even promote it. This same research has also documented that nudges are neither easy to implement nor a facile means of changing behaviour - a finding that, although disappointing for nudging enthusiasts, does at least imply that the risk of government manipulation via nudging is far lower than hitherto assumed. By closely examining these fresh insights from the WINK project, we are able to suggest new opportunities for identifying when and for whom nudge interventions will be preferable to more conventional public policy arrangements. 
In doing so, we will not focus on different types of nudges, but rather use the generic term 'nudge' to describe a diversity of interventions that may differ in scope and design, but have in common the aim of gently steering a choice without forbidding the alternative option (Thaler \& Sunstein, 2008). Although we are aware that different categorizations have been proposed with possibly differential underlying mechanisms for specific types of nudges (e.g., Dolan et al., 2012; Münscher et al., 2016), to date there is no widely accepted classification of nudging techniques (Marchiori et al., 2017). Moreover, we posit that considerations of ethics, implementation and effectiveness apply to nudges in general, despite their specific features, because there is no unidimensional framework that would predict in what way these reflections interrelate. For instance, whereas a default nudge for organ donation registration may be relatively easy to design and is generally considered to be effective (Johnson \& Goldstein, 2003), it can still raise significant political and ethical debate about implementation - which would compromise the efficiency of this approach in public policy (Bramhall, 2011; https:/www.debatingeurope.eu/ 2017/03/30/everyone-considered-organ-donors-unless-opt/\#.XkPhGWhKg2w). In a similar vein, a nudge to promote decreased meat consumption in cafeterias may be a little harder to design but can still be relatively easy to implement, whereas the effects may be relatively weak (Cadario \& Chandon, 2019). Having said this, we acknowledge that different nudges may speak to different psychological mechanisms. For instance, the typical case of defaults illustrates that it is not easy to discern how this nudge operates on a psychological level, as it is uncertain whether a default speaks to inertia (Smith et al., 2013), implicit recommendation (McKenzie et al., 2006) or a reference point (Park et al., 2000). Yet, for the specific purpose of this review examining the assumptions that dictate the discussion on the legitimacy of nudging as a public policy instrument, we will consider the generic concept of nudges.

\section{Autonomous choice}

Because autonomous choice is the cornerstone of democratic liberal societies and an essential requirement for individual well-being (Inglehart et al., 2008; Ryan \& Deci, 2000), the most prominent criticism in ethical debates on nudging is that nudges may violate autonomous choice through patronization or manipulation (Bovens, 2009; Hansen \& Jespersen, 2013; Wilkinson, 2013; Baldwin, 2014). Yet if nudges do not impose a choice, proponents respond: how can they be violating autonomy? In a recent study, we reconciled this dichotomy by revealing that different authors have different conceptions of autonomy (Vugts et al., 2018), although most concerns about nudging's violation of autonomy originate from a classic Millian view of the latter as 
unrestricted freedom of choice (Mill, 1999). From this perspective, making certain choice options more or less prominent may prevent individuals from choosing freely among the available alternatives. Our analysis, in contrast, identified other notions of autonomy that depart from this classical view, including autonomy as agency, which involves an individual's capacity to choose, and autonomy as self-constitution, which relates to individual identity and living the life one wants (Korsgaard, 2009).

Although these finer distinctions have been previously noted in the literature, autonomy as agency and, to a lesser extent, as self-constitution are in fact the most endorsed ways of thinking about how nudges relate to autonomy (Vugts et al., 2018). As a result, the implications of the multiple approaches to autonomy have not yet been considered in full. Viewed from the autonomy-asagency perspective, nudging not only allows for 'autonomous choice' - that is, selecting an alternative option without significant cost or effort (Thaler \& Sunstein, 2008) - but can even facilitate the choice that individuals would have made given the opportunity (Saghai, 2013). By the same token, nudging may support individuals in making a preferred choice that agrees with their identity (i.e., is in line with their personal goals), but that they would otherwise not have made because of being confused by a multitude of options (Markus \& Schwartz, 2010). Take, for example, someone who wants to eat healthy snacks in between meals as a replacement for unhealthy snacks (as many people intend but not often manage to do; Verhoeven et al., 2012), but who sees no opportunities to enact this plan because outlets are packed with unhealthy snacks. Making healthy snacks more accessible by a proximity nudge (Kroese et al., 2015; Van Gestel et al., 2018) would help this person to consider the alternatives in a more balanced way and thus strengthen their agency insofar as the more prominent placement of the healthy option increases the opportunity to act in accordance with their intention, which would in turn contribute to their healthy-eater identity.

Viewed from the perspectives of autonomy-as-agency and autonomy-as-selfconstitution, a choice arrangement that enables individuals to do as they wish may help them live their lives without continual deliberation on how to enact their intentions. It has therefore been argued that making one option more prominent does not undermine autonomy, but rather may actually increase it. That is, the sheer unlimited freedom of choice in many situations may compromise deliberative decision-making capacities and create uncertainty about what to choose, resulting eventually in decision fatigue (Markus \& Schwartz, 2010; Schwartz \& Cheek, 2017). It has even been suggested that many citizens would probably "thank public officers for making the choice easy for them" (John, 2018, p. 110).

As regards such citizen approval, studies on the acceptance of nudges have in fact shown that, to the extent that 'soft' paternalism is better appreciated than 
hard paternalistic imposition of a specific 'choice' (Schroeder et al., 2017), individuals value choice support via nudges both in hypothetical scenarios (Diepeveen et al, 2013; Junghans et al., 2015; Reisch \& Sunstein, 2016; Sunstein et al., 2017) and in real-life settings (Kroese et al., 2015; Van Gestel et al., 2018). Nonetheless, the appreciation of nudges as they relate to autonomy is strongly influenced by how they are explained to nudgees. In particular, when the emphasis lies on describing the purpose of the nudge (e.g., "We help you to make a healthy choice"; Junghans et al., 2015; Kroese et al., 2015), respondents tend to voice positive attitudes. However, when the explication emphasizes that nudges operate via unconscious influences, respondents tend to show more concern (Wachner et al., 2020). This observation not only holds for nudges. It has been shown that any description alerting people to potential negative consequences (e.g., manipulation) generally leads to unequivocal disapproval (Kareev \& Trope, 2011). Studies in which people were merely made aware of the presence or purpose of a nudge - either defaults (Bruns et al., 2018) or positioning (Kroese et al., 2015) - suggest that they find choice support as such not to be disconcerting (Loewenstein et al., 2015; Reisch \& Sunstein, 2016; Paunov et al., 2018; Wachner et al., 2020).

These differently focused observations demonstrate that nudges may empower individuals to make their actual preferred choices rather than succumbing to the well-documented intention-behaviour gap in which inertia, distraction or brief moments of failing willpower result in non-enactment of about $40 \%$ of intentions (Sheeran, 2002). These different understandings of autonomy also have important implications for the implementation of nudging in public policy, which has prompted concerns of violating liberal democratic principles by luring individuals into unwanted choices (Grüne-Yanoff, 2012). The potential ability of nudging to increase autonomy by enhancing individual agency or self-constitution would not only legitimize the use of behavioural insights in public policy, but also provide strong support for even greater use.

Before discussing the implications of these new autonomy definitions for the debate on nudge effectiveness and nudge implementation in public policy, however, we need to address one other issue that applies to nudging proponents and critics alike. That is, both seemingly endorse individual autonomy as the essential value for judging the use of nudges, implying that less restrictive policies are always preferable over more restrictive options to accommodate citizen autonomy. Yet more restrictive policies have been defended as offering even better opportunities for citizens to act on their personal goals, with beneficial consequences for both individuals and the society as a whole (Conley, 2012). Indeed, it has been argued that nudges may also put too much responsibility on individuals where governments should consider paternalistic 
measures in cases where individuals have little control over their choices (Verweij \& Van den Hoven, 2012). It is therefore urgent to broaden the autonomy debate from nudges potentially violating personal autonomy to nudges shifting too much responsibility from the state to the individual (Jones et al., 2013).

Even more importantly, those wishing to implement nudging must take into account other values that inform government policies, including the principles related to solidarity and justice, in which such services as health care and pension programmes are rooted. Highlighting individual autonomy without considering the common good may undermine solidarity and violate the idea that public policies should be beneficial to all, engendering the argument that nudging's ability to benefit the collective should figure more prominently in nudge design (Lynne et al., 2016; Van der Linden, 2018). Given the recognition that values like solidarity and protection from harm are crucial parameters of public policy, there is an urgent need to replace the current focus on autonomy with an emphasis on incorporating these values into any consideration of nudging legitimacy. Discussion of the ethical permissibility of nudges would further benefit from debate on the safeguards that have to be built into the legal and political arrangements for employing nudges in public policy in order to bring them in line with constitutional rule of law values (McCrudden \& King, 2016).

\section{Easy implementation}

Increasing governmental interest in supplementing traditional public policy instruments (e.g., regulation or incentives) with behavioural insights to influence citizen support for public priorities and corresponding policies is exemplified by the early installation of national behavioural insight units in both the UK (2010) and the USA (Obama, 2015). In the first instance, former UK Prime Minister David Cameron was so impressed by Thaler and Sunstein's book that he recommended it to all conservative Members of Parliament (McSmith, 2010). Today, an estimated 135 behavioural insights units are in place worldwide, although not all are active in actually designing and implementing interventions (Whitehead et al., 2014).

This popularity of the nudge concept in governmental circles is driven by the belief that successful policies in such important areas as taxing, traffic and sustainability rely on citizen behavioural commitment. For example, a government wanting to reduce $\mathrm{CO}_{2}$ emissions to meet the Paris climate agreement requirements of 2015 must consider whether citizens can act in accordance with policy objectives and replace grey energy contracts with green ones, install solar screens on their roofs and prioritize using public transport over their own 
cars (OECD, 2017). Designing policies without considering citizen ability to meet their requirements - what the Netherlands Scientific Council for Government Policy refers to as 'citizen capacity to act' (Keizer et al., 2019) - fails to engage the public in policy objectives and renders the policies less effective.

Not only are behavioural insights required for the design of more effective policies when individual choices matter, but the popularity of nudging among policymakers also appears to be related to the apparent opportunities for easy implementation that would make these policies more efficient (Sanders et al., 2018). That is, they see nudges as 'fast and furious' (Haynes et al., 2012) interventions that teams of behavioural science experts can easily add into existing policies as ready-to-use devices (Benartzi et al., 2017). They also consider these teams' tasks as relatively straightforward in terms of 'designing a behavioural intervention, testing this intervention rapidly and inexpensively, and then widely implementing the strategies that prove most effective' (Benartzi et al., 2017; cf., Service et al., 2014). In reality, however, the process of designing, testing and implementing nudge interventions is far more complicated, which questions the supposed 'efficiency' of nudges.

One recurring theme in discussions about behavioural policymaking is the extent to which nudge design and implementation should follow a systematic procedure, of which quick testing is a critical element (Lunn, 2012; John, 2014; Lepenies et al., 2018). The typical behaviour expertise approach would be to place the problem under behavioural scrutiny, design and disseminate a nudge based on observations and then evaluate its effectiveness as an intervention (Haynes et al., 2012). Public policy arrangements, however, are rarely designed so linearly, depending rather on (un)planned changes at many different layers and with various policy actors (Cairney, 2017). Consequently, the empirical cycle that behavioural experts usually employ in designing interventions does not map well onto the reality of public policymaking as part of a political process marked by compromise (Feitsma, 2018; John \& Stoker, 2019).

These discrepancies were clearly made manifest in an elaborate ethnographic study - involving multiple behavioural insight units - that documented the organization of behavioural expertise in governmental circles (Ball \& Feitsma, 2019; Feitsma, 2019). This study identified myriad ways of incorporating behavioural science insights into existing policymaking procedures, including informal networks of small groups of nudge adepts, more elaborate discussion groups of public policy officers, the availability of in-house experts for consultation, the hiring of external consultants and training for large groups of public policy officers on the basics of nudging (Ball \& Feitsma, 
2019; Feitsma \& Schillemans, 2019; cf., Whitehead et al., 2014). The research also revealed, however, that only about half of those in behavioural insight units (specifically, those employed in larger units) had a professional background in behavioural science (psychology or behavioural economics; Feitsma, 2019). As a result, many teams were spending a great deal of time discussing the potentials of nudging without explicitly planning nudge design and implementation, sometimes even focusing primarily on clarifying nudges as a fuzzy concept (Feitsma, 2019).

Such variations in behavioural insight unit operation illustrate that, in spite of growing recognition of the relevance of behavioural insights, uncertainty remains about how the nudge concept should be integrated into existing protocols and procedures for public policymaking. Yet if treated as standalone interventions implemented in isolation without consideration of the wider policymaking context, nudges will be less effective. Hence, there is an urgent need to develop formats that support the integration of behavioural expertise into public policy (Hansen, 2018; Sanders et al., 2018), a topic largely neglected in behavioural public administration research, which seems more concerned with adopting behavioural insights than with implementing them (Grimmelikhuijsen et al., 2017).

This need for more sophisticated implementation formats is even more urgent given the shift in most policymaking areas from singular governmental action to more complex governance by multiple actors, including external parties (Peters \& Pierre 2001; Levi-Faur, 2014). In these cases, policymakers are not the unique choice architects responsible for setting the conditions for individual choice, but rather must collaborate with public organizations, corporations, non-profit organizations and civil communities. This scenario is even more likely when governments operate as 'meta-choice architects' (Jessop, 2003) influencing how direct choice architects may or may not nudge individuals towards desired behaviours.

All of the above observations highlight the naïveté of viewing nudges as a means of easy policymaking. Rather, acknowledging that public policymaking is an integral part of the political process has major implications for the development of procedures for nudge implementation. First, governments considering the use of nudge interventions to achieve policy objectives dependent on citizen commitment should be aware that these interventions require democratic control procedures well beyond the cycle of developing, testing and implementing simple (often small) discrete nudge interventions (Button, 2018; Lepenies et al., 2018). In fact, successfully incorporating nudges into existing policies requires not only that nudge design and implementation adequately account for the value judgements and ethical considerations of public policy's regular democratic processes, but also that the conception of 
autonomy goes well beyond the conventional notion of free choice to emphasize the aspects of agency and identity. A more explicit consideration of how nudges can increase decision-making competence and self-reliance will open up new avenues for nudge design and implementation in public policy (cf., Hertwig \& Grüne-Yanoff, 2017).

\section{Ease of accomplishing behavioural change}

A central assumption in the nudge literature is that because nudges speak to 'fast' non-analytical system 1 reasoning (Thaler \& Sunstein, 2008), they easily influence behaviour and produce straightforward, predictable effects on decision-making. In fact, the popularity of nudging interventions among scholars and policymakers is largely due to the disappointing results from persuasion-directed behavioural change interventions that rely on 'slow' analytical system 2 processing (Marchiori et al., 2017). That is, the notion that nudging, by bypassing the need to process all choice pros and cons, enables less effortful decision-making has generated high expectations of nudging as a promising alternative for more traditional interventions (Marteau et al., 2012). Nevertheless, whereas nudge proponents consider the potentially large nudge effect from simple interventions to be a major advantage (Martin et al., 2014; Service et al., 2014), nudge critics fear it may lead to government exploitation of reasoning flaws, especially in individuals unaware of their decisions being influenced (John et al., 2009).

Yet even when nudges are used, choices are not as easily modified as generally assumed (Gigerenzer, 2015), with several meta-analyses demonstrating that nudging effects are relatively modest regardless of nudge type and/or target behaviour (Hollands et al. 2013; Szaszi et al., 2018; Cadario \& Chandon, 2019; Hummel \& Maedche, 2019). One possible explanation for this is the contingency of nudge effects on individual goals and plans. Yet little empirical research to date has explicitly tested the oft-repeated claim that nudges are only acceptable when aligned with existing preferences (Bovens, 2009), although recent investigations have demonstrated that the impact of nudges on behaviour is critically dependent on these preferences. For example, a default nudge to automatically transfer taxpayer refunds into a savings account proved ineffective when the recipients had already made plans to spend them (Bronchetti et al., 2013). Likewise, a centre-stage nudge that positioned the 'wise' choice (a small soft drink) in the middle (between medium and large options) to encourage less consumption of sugary soft drinks proved ineffective when excessive customer thirst produced a (nudgeincongruent) preference for large portions. This nudge was also made redundant in those with a strong health goal by a pre-existing (nudge-congruent) 
preference for a small soft drink (Venema et al., 2019). In fact, nudges exert the strongest influence when individuals are uncertain or ambivalent about their choices and in need of choice support, as in the case of conflicting preferences (Venema et al., 2020a). Given the ethical debate on nudges potentially violating autonomous choice, these findings provide initial evidence that nudging may support action on 'medium-size' preferences (autonomy as self-constitution) and provide assistance in cases of decision uncertainty (autonomy as agency).

These new insights into 'nudgeability' (i.e., sensitivity to the influence of nudges; de Ridder et al., 2020; cf., Goldin, 2015) call for further scrutiny of the processes supposedly underlying nudge effectiveness. One crucial empirical finding in this regard is that, contrary to the prevailing assumption, nudges may not exclusively target system 1 processing, implying that nudge effectiveness is not dependent on the decision-maker being in a system 1 processing mode. Rather, nudges have proven equally effective under low or high self-control (Hunter et al., 2018), low or high cognitive load (Bruns, 2019) and presence or absence of distraction or fatigue (Cheung et al., 2017). In addition, despite the classic assumption that nudge effectiveness stems from recipient unawareness, explicit explanation of nudging's use does not render it ineffective (Kroese et al., 2015; Loewenstein et al., 2015; Bruns et al., 2018; Paunov et al., 2018; Van Gestel et al., 2018; Wachner et al., 2020), which again suggests that nudges remain effective even in the presence of an opportunity to deliberate.

An alternative proposal is that system 2 nudges, which directly address the human capacity for reasoning and reflection, should be more effective - and more appreciated by the general public (Sunstein, 2016) - because they can increase self-knowledge and decision-making competence (Hertwig, 2017; Hertwig \& Grüne-Yanoff, 2017). These findings align with an emerging understanding of the system 1-system 2 processing dichotomy, the theoretical framework that has informed nudging interventions. Debate is increasing on whether human behaviour is indeed governed by two separate systems (Melnikoff \& Bargh, 2018; Bago \& De Neys, 2019) or whether it may be more accurate to talk about fast and slow thinking processes that do not necessarily operate in concert. Put simply, behaviour can be automatic (characteristic of system 1) while still being goal directed (characteristic of system 2). On the other hand, little evidence exists for the notion that fast, automatic processing is irrational or that slow, controlled thinking is inherently intentional. Thus, positioning nudging as a tool to influence behaviour by appealing to system 1 processing may not be accurate given its disregard of the human behavioural complexities not adequately captured by a strict dual system perspective. For nudging research, this revamped conceptualization of dual process theories 
bears important implications. Indeed, a recent study has suggested that nudges are equally effective regardless of whether people have the capacity to engage in careful thought or not (Van Gestel et al., 2020).

Whereas the insight that nudge effectiveness depends on individual preferences may be disappointing to those who see nudges as a magic bullet, this finding is of great importance to the debate on boundary conditions for nudge implementation in public policy. Equally important is the finding that transparency via explicit notification that nudges are in use does not reduce their effectiveness. The fact that both of these debates centre on the question of whether nudges manipulatively take advantage of system 1 processing thereby implicitly positioning governments as marketers of their own public policy agendas - in fact turns the seemingly negative message of lower-thanassumed nudge effectiveness into a positive for the continuing dispute over their legitimacy as a policy instrument. Viewed from this positive perspective, nudging has the potential to assist public policy officers struggling with implementation issues to determine when, how and for whom nudges should be employed. Guidelines for policymakers to deal with these pressing issues are required (Hertwig, 2017).

These insights also generate new directions for the psychological research on nudging, whose finding that attempts to influence decisions are critically dependent on individual preferences and other moderators is based primarily on experimental examination of relatively trivial choices in artificial lab settings with a focus on immediate effects. It is thus urgent that such research begins to address the impact of nudges on major decisions with significant long-term impacts on citizens' lives, including field experiments with underprivileged populations facing critical choices on health, finance and wellbeing (Mani et al., 2013; Ghesla et al., 2018; Gillebaart \& de Ridder, 2019). When conducting these latter experiments, researchers should also assess the acceptability of nudging interventions within these populations. At the same time, to avoid exclusive focus on when and how nudges are effective - which risks the provision of technocratic solutions for public policy issues - psychological research should emphasize the immediate versus the long-term effects of nudging beyond mere efficient steering of behaviour. By doing so, it can supplement the existing survey opinion data with critical insights into when and how nudges contribute to crucial behavioural regulation parameters, including decision-making competence, self-rule and capacity to act.

\section{Discussion}

Having critically reviewed three assumptions that dominate multidisciplinary perspectives on the nudging debate - that nudges are a simple, effective 
means for steering individual choices; that they are easily implemented in public policy; but that they represent a possible threat to autonomous decision-making - we conclude that none is supported by recent research on the ethical, public administration and psychological aspects of nudging. Rather, nudges are ethically more legitimate than is often assumed, but that they are dependent for their effectiveness on boundary conditions and are far from easy to implement. As regards the inherent assumption that autonomy is central to evaluating nudges as a public policy instrument, we identify a new understanding of autonomy as agency or self-constitution that strongly suggests nudging's potential to contribute to autonomy by increasing decisionmaking competence and helping individuals act upon their own priorities and preferences.

The recent research also provides increasing support for considering values beyond individual autonomy (e.g., solidarity) when judging the suitability of nudging as a public policy instrument. At the same time, the evidence that nudges should not be implemented as standalone interventions in existing policies refutes the assumption that nudge interventions are easily integrated into public policy. In reality, because public policymaking is part of a political process characterized by compromise between multiple actors, nudge implementation requires more sophisticated formats than are currently available. Finally, recent evidence that individual goals and plans are important moderators of nudge effectiveness negates the belief that nudge interventions have straightforward effects on behaviour, especially given emerging evidence that such effectiveness does not rely on a system 1 mode of thinking. Rather, nudges can also be effective when recipients are aware of their presence and have the opportunity to reflect on their choices.

These insights offer an important lesson for psychologists who tout nudge effectiveness without considering its acceptability by public policymakers and the general public and who pay insufficient attention to real-life effectiveness beyond the clean lab setting. At the same time, knowing more about the boundary conditions of nudge effectiveness may inform ethical debates on nudging's potential violation of individual autonomy, pointing rather to its potential to boost autonomous decision-making by providing better opportunities for preferred action. This latter should soften ethical concerns about government manipulation and prompt ethicists to recognize the possibility of public appreciation for choice support. Both psychologists and ethicists should also be more aware of the need for more complex procedures in the public policy context than simple implementation of nudges as standalone interventions. In particular, given both groups' current focus on the large issues of autonomy and effectiveness, both may underestimate the potentially serious outcomes of public policy officers' attempts to incorporate behavioural insights into policy 
arrangements. These practicalities are thus part of an incremental process that is informative to anyone unfamiliar with or neglectful of the nuts and bolts of policymaking.

\section{Conclusion}

An integrated perspective on the merits and boundary conditions of nudging interventions has important implications for the debate on nudging legitimacy as a public policy instrument. Acknowledging that nudges may contribute to autonomous decision-making is critical in deciding when nudges should be implemented because of their ability to engage the public in such important public policy issues as public health, climate change and migration, all of which involve more than a subtle steering of individual choice. This acknowledgement also means, however, that studies on nudging effectiveness should move beyond the mere investigation of whether nudges lead to desired choices and incorporate measures of agency and self-constitution to assess whether nudges are truly capable of increasing citizen involvement. Likewise, the realization that public policymaking requires more complex implementation procedures than regular behavioural interventions calls for behavioural experts and public policymakers to develop new methods of collaboration. Lastly, the recognition that nudge effectiveness is not as heavily reliant on an unreflective mind state as once thought should encourage ethicists to soften their critical evaluations while inspiring public policymakers to gear their interventions towards public policies that recognize citizens as competent decisionmakers. Overall, then, an integrated perspective can foster the consideration of nudges in terms of autonomous choices that align with individual preferences while also improving chances for implementation by helping public policy officers overcome their hesitation as to when and how a nudge is preferable over more conventional public policy interventions.

\section{Financial support}

This research was funded by the Netherlands Organization for Scientific Research (grant number 407-13-030).

\section{References}

Bago, B. and W. De Neys (2019), 'The Smart System 1: Evidence for the intuitive nature of correct responding on the bat-and-ball problem', Thinking and Reasoning, 25: 257-299. doi: ff10.1080/13546783.2018.1507949ff. ffhal-02106554f 
Baldwin, R. (2014), 'From regulation to behavior change: Giving nudge the third degree', Modern Law Review, 77: 831-857. doi: 10.1111/1468-2230.12094

Ball, S. and J. N. P. Feitsma (2019), 'The boundaries of behavioral insights: Observations from two ethnographic studies', Evidence and Policy. doi: 10.1332/174426419X15643724702722

Benartzi, S., J. Beshears, K. L. Milkman, C. R. Sunstein, R. H. Thaler, M. Shankar, W. Tucker-Ray, W. J. Congdon and S. Galing (2017), 'Should governments invest more in nudging?', Psychological Science, 28: 1041-1055. doi: 10.1177/0956797617702501

Bovens, L. (2009), The ethics of nudge, in T. Grüne-Yanoff and S. O. Hansson (eds), Preference change: Approaches from philosophy, economics and psychology, New York: Springer, 207-219.

Bramhall, S. (2011), 'Presumed consent for organ donation: A case against', Annals of The Royal College of Surgeons of England, 93: 270-272. doi: 10.1308/147870811X571136b

Bronchetti, E. T., T. S. Dee, D. B. Huffman and E. Magenheim (2013), 'When a nudge isn't enough: Defaults and saving among low-income tax filers', National Tax Journal, 66: 609-635. doi: $10.3386 / \mathrm{w} 16887$

Bruns, H. (2019), No evidence that distracted people are easier to nudge. An experiment on the interaction of cognitive scarcity and defaults in a public goods game. Retrieved from http://dx.doi. org/10.2139/ssrn.3417145

Bruns, H., E. Kantorowicz-Reznichenko, K. Klement, M. L. Jonsson and B. Rahali (2018), 'Can nudges be transparent and yet effective?', Journal of Economic Psychology, 65: 41-59. doi: 10.1016/j.joep.2018.02.002

Button, M. (2018), 'Bounded rationality without bounded democracy: Nudges, democratic citizenship, and pathways for building civic capacity', Perspectives on Politics, 16: 1034-1052. doi: $10.1017 /$ S1537592718002086

Cadario, R. and P. Chandon (2019), 'Which healthy eating nudges work best? A meta-analysis of field experiments', Marketing Science. doi: 10.1287/mksc.2018.1128

Cairney, P. (2017), 'Evidence-based best practice is more political than it looks: A case study of the 'Scottish Approach”, Evidence \& Policy, 13: 499-515. doi: 10.1332/174426416X14609261565901

Cheung, T. T., F. M. Kroese, B. M. Fennis and D. T. D. de Ridder (2017), 'The Hunger Games: Using hunger to promote healthy choices in self-control conflicts', Appetite, 116: 401-409. doi: 10.1016/j.appet.2017.05.020

Conly, S. (2012), Against autonomy, Cambridge University Press.

de Ridder, D. T. D., F. M. Kroese and L. C. Van Gestel (2020), Nudgeability: Mapping conditions of susceptibility to nudge influence. [Manuscript under review]

Diepeveen, S., T. Ling, M. Suhrcke, M. Roland and T. M. Marteau (2013) 'Public acceptability of government intervention to change health-related behaviors: A systematic review and narrative analysis', BMC Public Health, 756: 17. doi: 10.1186/1471-2458-13-756

Dolan, P., M. Hallsworth, D. Halpern, D. King, R. Metcalfe and I. Vlaev (2012), 'Influencing behaviour: The Mindspace way', Journal of Economic Psychology, 33: 264-277. doi: 10.1016/j. joep.2011.10.009

Feitsma, J. N. P. (2018), “Rationalized incrementalism'. How behavior experts in government negotiate institutional logics', Critical Policy Studies, doi: 10.1080/19460171.2018.1557067

Feitsma, J. N. P. (2019), 'Brokering behavior change: The work of behavioral insights experts in government', Policy \& Politics, 47: 37-56. doi: 10.1332/030557318X15174915040678

Feitsma, J. N. P. and T. Schillemans (2019), Behavior experts in government: From newcomers to professionals?, in H. Strassheim and S. Beck (eds), Handbook of Behavioral Change and Public Policy, Edward Elgar Publishing, 122-137).

Ghesla, C., M. Grieder and R. Schubert (2018), Nudging the poor and the rich - A field study on the distributional effects of green electricity defaults. doi: 10.2139/ssrn. 3147028

Gigerenzer, G. (2015), 'On the supposed evidence for libertarian paternalism', Review of Philosophy and Psychology, 6: 361-381. doi: 10.1007/s13164-015-0248-1 
Gillebaart, M. and D. T. D. de Ridder (2019), 'Distinguishing between self-control and perceived control over the environment to understand disadvantaged neighbourhood health and lifestyle outcomes', Psychology \& Health. doi: 10.1080/08870446.2019.1591409

Goldin, J. (2015), 'Which way to nudge? Uncovering preferences in the behavioral age', The Yale Law Journal, 125: 226-270. doi: 10.2139/ssrn.2570930.

Grimmelikhuijsen, S., S. Jilke, A. L. Olsen and L. Tummers (2017), 'Behavioral Public Administration: Combining insights from public administration and psychology', Public Administration Review, 77: 45-56. doi: 10.1111/puar.12609

Grüne-Yanoff, T. (2012), 'Old wine in new casks: Libertarian paternalism still violates liberal principles', Social Choice and Welfare, 38: 635-645. doi: 10.1007/s00355-011-0636-0

Halpern, D. (2015), Inside the nudge unit. How small changes can make a big difference, London: Ebury Publishing.

Hansen, P. G. (2018), 'What are we forgettin-?', Behavioral Public Policy, 2: 190-197. doi: 10.1017/ bpp.2018.13

Hansen, P. G. and A. M. Jespersen (2013), 'Nudge and the manipulation of choice: A framework for the responsible use of the nudge approach to behavior change in public policy', The European Journal of Risk Regulation, 1: 3-28. doi: 10.1017/S1867299X00002762

Hausman, D. M. and B. Welch (2010), 'Debate: To nudge or not to nudge', The Journal of Political Philosophy, 18: 123-136. doi: 10.1111/j.1467-9760.2009.00351.x

Haynes, L., B. Goldacre and D. Torgerson (2012), Test, learn, adapt: Developing public policy with randomised controlled trials, London: Cabinet Office - Behavioral Insights Team.

Hertwig, R. (2017), 'When to consider boosting: Some rules for policy-makers', Behavioral Public Policy, 1: 143-161. doi: 10.1017/bpp.2016.14

Hertwig, R. and T. Grüne-Yanoff (2017), 'Nudging and boosting: Steering or empowering good decisions', Perspectives on Psychological Science, 12: 973-986. doi: 10.1177/1745691617702496

Hollands, G. J., I. Shemilt, T. M. Marteau, S. A. Jebb, M. P. Kelly, R. Nakamura, et al. (2013), 'Altering choice architecture to change population health behavior: A large-scale conceptual and empirical scoping review of interventions within microenvironments', BMC Public Health, 13: 1218. doi: 10.1186/1471-3458-13-1218

Hummel, D. and A. Maedche (2019), 'How effective is nudging? A quantitative review on the effect sizes and limits of empirical nudging studies', Journal of Behavioral and Experimental Economics, 80: 47-58. doi: 10.1016/j.socec.2019.03.005

Hunter, J. A., G. J. Hollands, D. Couturier and T. M. Marteau (2018), 'Effect of snack-food proximity on intake in general population samples with higher and lower cognitive resource', Appetite, 121: 337-347. doi: 10.1026/j.appet.2017.11.101

Inglehart, R. F., R. Foa, C. Peterson and C. Welzel (2008), 'Development, freedom, and rising happiness: A global perspective (1981-2007)', Perspectives on Psychological Science, 3: 264-285. doi: $10.1111 / \mathrm{j} .1745-6924.2008 .00078 . \mathrm{x}$

Jessop, B. (2003), Governance and meta-governance: On reflexivity, requisite variety and requisite irony, in H. Bang (ed.), Governance as social and political communication, Manchester: Manchester University Press, 101-116.

John, P. (2014), 'Policy entrepreneurship in UK central government: The behavioral insights team and the use of randomized controlled trials', Public Policy and Administration, 29: 257-267. doi: $10.1177 / 0952076713509297$

John, P. (2018), How Far to Nudge? Assessing Behavioral Public Policy, Cheltenham/Northampton: Edward Elgar Publishing.

John, P., G. Smith and G. Stoker (2009), 'Nudge nudge, think think. Two strategies for changing civic behavior', The Political Quarterly, 80: 361-370. doi: 10.1111/j.1467-923X.2009.02001.x

John, P. and G. Stoker (2019), 'Rethinking the role of experts and expertise in behavioral public policy', Policy \& Politics, 47: 209-226. doi: 10.1111/j.1467-923X.2009.02001.x 
Johnson, E. J. and D. G. Goldstein (2003), 'Do defaults save lives?', Science, 302: 1338-1339.

Johnson, E. J., S. B. Shu, B. G. C. Dellaert, C. Fox, D. G. Goldstein, G. Häubl, R. P. Larrick, J. W. Payne, E. Peters, D. Schkade, B. Wansink and E. U. Weber (2012), 'Beyond nudges: Tools of a choice architecture', Marketing Letters, 23: 487-504. doi: 10.1007/s11002-012-9186-1

Jones, R., J. Pykett and M. Whitehead (2013), Changing behaviors. On the rise of the psychological state, Cheltenham/Northampton: Edward Elgar Publishing.

Junghans, A. F., T. T. L. Cheung and D. T. D. de Ridder (2015), 'Under consumers' scrutiny. An investigation into consumers' attitudes and concerns about nudging in the realm of health behavior', BMC Public Health, 15: 336. doi: 10.1186/s12889-015-1691-8

Kahneman, D. (2003), 'A perspective on judgment and choice: Mapping bounded rationality', American Psychologist, 58: 697-720. doi: 10.1037/0003-066X.58.9.697

Kareev, Y. and Y. Trope (2011), 'Correct acceptance weighs more than correct rejection: A decision bias induced by question framing', Psychonomic Bulletin \& Review, 18: 103-109. doi: 10.3758/s13423-010-0019-z

Keizer, A. G., W. Tiemeijer and M. Bovens (2019), Why knowing what to do is not enough. A realistic perspective on self-reliance, Springer Open.

Korsgaard, C. M. (2009), Self-constitution: Agency, identity, and integrity, Oxford: Open University Press.

Kroese, F. M., D. R. Marchiori and D. T. D. de Ridder (2015), 'Nudging healthy food choices: A field experiment at the train station', Journal of Public Health, 38: 133-137. doi: 10.1093/pumed/ fdv096

Leggett, W. (2014).The politics of behavior change: Nudge, neoliberalism and the state', Policy and Politics, 42: 3-19. doi: 10.1093/pubmed/fdv096

Lepenies, R., K. Mackay and M. Quigley (2018), 'Three challenges for behavioral science and policy: The empirical, the normative and the political', Behavioral Public Policy, 2: 174-182. doi: $10.1017 / \mathrm{bpp} .2018 .18$

Loewenstein, G., C. Bryce, D. Hagmann and S. Rajpal (2015), 'Warning: You are about to be nudged', Behavioral Science \& Policy, 1: 35-42. doi: 10.1353/bsp.2015.0000

Lunn, P. (2012), 'Behavioral economics and policy making: Learning from the early adopters', The Economic and Social Review, 43: 423-449. https://EconPapers.repec.org/RePEc:eso:journl: v:43:y:2012:i:3:p:423-449

Lynne, G. D., N. V. Czap, H. J. Czap and M. E. Burbach (2016), 'A theoretical foundation for empathy conservation: Toward avoiding the tragedy of the commons', Review of Behavioral Economics, 3: 243-279. doi: 10.1561/105.00000052

Mani, A., S. Mullainathan, E. Shafir and J. Zhao (2013), 'Poverty impedes cognitive function', Science, 341(6149): 976-980. doi: 10.1126/science.1238041

Marchiori, D. R., M. A. Adriaanse and D. T. D. de Ridder (2017), 'Unresolved questions in nudging research: Putting the psychology back in nudging', Social and Personality Psychology Compass, 11: e12297. doi:10.1111/spc3.12297

Markus, H. R. and B. Schwartz (2010), 'Does choice mean freedom and well-being?', Journal of Consumer Research, 37: 344-355. doi: 10.1086/651242

Marteau, T. M., G. J. Hollands and P. C. Fletcher (2012), 'Changing human behavior to prevent disease: The importance of targeting automatic processes', Science, 337: 1492-1495. doi: $10.1126 /$ science. 1226918

Martin, S. J., N. Goldstein and R. Cialdini (2014), 'The small big: Small changes that spark big influence', London: Hachette.

McCrudden, C. and J. King (2016), The dark side of nudging: The ethics, political economy, and law of libertarian paternalism, in A. Kemmerer, C. Möller, M. Steinbeis and G. Wagner (eds), Choice architecture in democracies. Exploring the legitimacy of nudging, Baden Baden: Nomos, 75-139. 
McKenzie, C. R., M. J. Liersch and S. R. Finkelstein (2006), 'Recommendations implicit in policy defaults', Psychological Science, 17: 414-420. doi: 10.1111/j.1467-9280.2006.01721.x

McSmith, A. (2010, August 12). "First Obama, now Cameron embraces 'nudge theory", The Independent.

Melnikoff, D. E. and J. A. Bargh (2018), 'The mythical number two', Trends in Cognitive Sciences, 22: 280-293. doi: 10.1016/j.tics.2018.02.001

Mill, J. S. (1999), On liberty, London: Longman. (Original work published 1859).

Münscher, R., M. Vetter and T. Scheuerle (2016), 'A review and taxonomy of choice architecture techniques', Journal of Behavioral Decision Making, 29: 511-524. doi: 10.1002/bdm.1897

Nys, T. and B. Engelen (2017), 'Judging nudging: Answering the manipulation objection', Political Studies, 65: 199-214. doi: 10.1177/0032321716629487

Obama, B. (2015), Executive order-Using behavioral science insights to better serve the American people. Retrieved from https:/www.whitehouse.gov/the-press-office/2015/09/15/executiveorder-using-behavioral-science-insights-betterserve-American.

OECD (2017), Behavioral Insights and Public Policy. Lessons from Around the World, Paris: OECD Publishing.

OECD (2018), BASIC - A practitioner's toolbox \& ethical guidelines for applying behavioral insights in public policy, Paris: OECD Publishing.

Park, C. W., S. Y. Jun and D. J. McInnis (2000), 'Choosing what I want versus rejecting what I do not want: An application of decision framing to product option choice decisions', Journal of Marketing Research, 37: 187-202. doi: 10.1509/jmkr.37.2.187.18731

Paunov, Y., M. Wänke and T. Vogel (2018), 'Transparency effects on policy compliance: disclosing how defaults work can enhance their effectiveness', Behavioral Public Policy, 2: 1-22. doi: 10.1017/bpp.2018.40

Reisch, L. A. and C. R. Sunstein (2016), 'Do Europeans like nudges?', Judgment and Decision Making, 11: 310-325. doi: 10.2139/ssrn.2739118

Ryan, R. M. and E. L. Deci (2000), 'Self-determination Theory and the facilitation of intrinsic motivation, social development, and wellbeing', American Psychologist, 55: 68-78. doi: 0.1037/l 0003-066x.55.1.68

Saghai, Y. (2013), 'Salvaging the concept of nudge', Journal of Medical Ethics, 39: 487-493. doi: 10.1136/medethics-2012-100727

Sanders, M., V. Snijders and M. Hallsworth (2018), 'Behavioral science and policy: Where are we now and where are we going?', Behavioral Public Policy, 2: 144-167. doi: 10.1017/bpp.2018.17

Schroeder, J., A. Waytz and N. Epley (2017), 'Endorsing help for others that you oppose for yourself: Mind perception alters the perceived effectiveness of paternalism', Journal of Experimental Psychology: General, 146: 1106-1125. doi: 10.1037/xge0000320

Schwartz, B. and N. N. Cheek (2017), 'Choice, freedom, and well-being: Considerations for public policy', Behavioral Public Policy, 1: 106-121. doi: 10.1017/bpp.2016.4

Service, O., M. Hallsworth and D. Halpern (2014), EAST: Four simple ways to apply behavioral insights. Retrieved from http://www.behaviouralinsights.co.uk/publications/east-four-simpleways-to-apply-behavioural-insights/

Sheeran, P. (2002), 'Intention-behavior relations: A conceptual and empirical review', European Review of Social Psychology, 12: 1-36. doi: 10.1080/14792772143000003

Smith, N. C., D. G. Goldstein and E. J. Johnston (2013), 'Choice without awareness: Ethical and policy implications of defaults', Journal of Public Policy and Marketing, 32: 159-172. doi: 10.1509/jppm.10.114

Sunstein, C. (2015), 'The ethics of nudging', Yale Journal on Regulation, 32: 6. Available at: http:// digitalcommons.law.yale.edu/yjreg/vol32/iss2/6.

Sunstein, C. R. (2016), 'People prefer System 2 nudges (kind of)', Duke Law Journal, 66: 121-168. doi: $10.2139 / \mathrm{ssrn} .2731868$ 
Sunstein, C. R., L. A. Reisch and J. Rauber (2017), A worldwide consensus on nudging? Not quite, but almost. Regulation and Governance. doi: 10.1111/rego.12161.

Szaszi, B., A. Palinkas, B. Palfi, A. Szollosi and B. Aczel (2018), 'A systematic scoping review of the choice architecture movement: Toward understanding when and why nudges work', Journal of Behavioral Decision Making, 31: 355-366. doi:10.1002/bdm.2035.

Thaler, R. H. and C. S. Sunstein (2008), 'Nudge', Improving decisions about health, wealth, and happiness. Penguin Books.

Van der Linden, S. (2018), 'The future of behavioral insights: On the importance of socially situated nudges', Behavioral Public Policy, 2: 207-217. doi:10.1017/bpp.2018.22

Van Gestel, L. C., M. A. Adriaanse and D. T. D. de Ridder (2020), 'Unraveling the effects of a default nudge under type 1 and type 2 processing', Comprehensive Results in Social Psychology (Preregistered Stage 1 Manuscript accepted for publication).

Van Gestel, L. C., F. M. Kroese and D. T. D. de Ridder (2018), 'Nudging at the checkout counter - A longitudinal study of the effect of a food repositioning nudge on healthy food choice', Psychology \& Health, 33: 800-809. doi: 10.1080/08870446.2017.1416116

Venema, T. A. G., F. M. Kroese, J. S. Benjamins and D. T. D. de Ridder (2020a), 'When in doubt, follow the crowd? Responsiveness to social proof nudges in the absence of clear preferences', Frontiers in Psychology Cognition, 11. doi:10.3389/fpsyg.2020.01385

Venema, T.A.G, F. M. Kroese, E. De Vet and D. T. D. de Ridder (2019), 'The one that I want: Strong personal preferences render the center-stage nudge redundant', Food Quality and Preference, 78: 103744. doi: 10.1016/j.foodqual.2019.103744

Venema, A. G., F. M. Kroese, B. Verplanken and D. T. D. de Ridder (2020b), 'The (bitter) sweet taste of nudge effectiveness: The role of habits in a portion size nudge, a proof of concept study', Appetite, 151. doi: 10.1016/j.appet.2020.104699

Verhoeven, A. A. C., M. A. Adriaanse, C. Evers and D. T. D. de Ridder (2012), 'The power of habits: Unhealthy snacking behavior is primarily predicted by habit strength', British Journal of Health Psychology, 17: 758-770. doi: 10.1111/j.2044-8287.2012.02070.x

Verweij, M. and Van den Hoven, M. (2012).Nudges in public health: Paternalism is paramount', American Journal of Bioethics, 12: 16-17. doi: 10.1080/15265161.2011.634489

Vugts, A., M. Van den Hoven, M. De Vet and E. Verweij (2018), 'How autonomy is understood in discussions on the ethics of nudging', Behavioral Public Policy, 2: 1-16. doi:10.1017/ bpp. 2018.5

Wachner, J., M. A. Adriaanse and D. T. D. de Ridder (2020), And how will that make you feel? Expectations about nudging affecting autonomy. [Manuscript under review]

Whitehead, M., R. Jones, R. Howell, R. Lilley and J. Pykett (2014), Nudging all over the World. Economic and Social Research Council of the UK.

Wilkinson, T. M. (2013), 'Nudging and manipulation', Political Studies, 61: 341-355. doi: 10.1111/ j.1467-9248.2012.00974.x

World Bank (2015), Mind, Society and Behavior, Washington: World Bank Group. 